\title{
Using TILs to Predict Therapeutic Effect of Chemotherapy (Pertuzumab, Trastuzumab, Docetaxel) on HER2-positive Breast Cancer
}

\author{
SHINICHIRO KASHIWAGI ${ }^{1}$, YUKA ASANO ${ }^{1}$, WATARU GOTO ${ }^{1}$, KOJI TAKADA ${ }^{1}$, \\ KATSUYUKI TAKAHASHI ${ }^{2}$, TAKAHARU HATANO ${ }^{3}$, TSUTOMU TAKASHIMA ${ }^{1}$, SHUHEI TOMITA ${ }^{2}$, \\ HISASHI MOTOMURA ${ }^{3}$, MASAHIKO OHSAWA ${ }^{4}$, KOSEI HIRAKAWA ${ }^{1}$ and MASAICHI OHIRA ${ }^{1}$ \\ ${ }^{1}$ Department of Surgical Oncology, Osaka City University Graduate School of Medicine, Osaka, Japan; \\ ${ }^{2}$ Department of Pharmacology, Osaka City University Graduate School of Medicine, Osaka, Japan; \\ ${ }^{3}$ Department of Plastic and Reconstructive Surgery, \\ Osaka City University Graduate School of Medicine, Osaka, Japan; \\ ${ }^{4}$ Department of Diagnostic Pathology, Osaka City University Graduate School of Medicine, Osaka, Japan
}

\begin{abstract}
Background/Aim: Recently, reports of the clinical implications of tumor-infiltrating lymphocytes (TILs) in breast cancer treatment have increased. We evaluated that chemotherapy with a TPD regimen (trastuzumab, pertuzumab, docetaxel) against HER2-positive breast cancer, using TILs as indicators. Patients and Methods: The subjects were 24 patients who had received TPD-chemotherapy. A semiquantitative evaluation of lymphocytes invading the stroma in needle biopsy specimens prior to treatment as TILs was conducted, after which, sensitivity to chemotherapy and patient prognosis were evaluated. Results: Overall response rate was significantly higher in the high-TILs group than in the low-TILs group. Significant extension of the progression-free survival (PFS) and overall survival was found in the high-TILs group compared to the low-TILs group. In addition, high TILs numbers significantly contributed to the extension of PFS. Conclusion: Monitoring antitumor immune response using TILs might be a useful indicator for predicting the curative effects of TPD chemotherapy for HER2-positive breast cancer.
\end{abstract}

Individualized chemotherapy for breast cancer is mainly used to treat intrinsic subtypes regulated by estrogen signals and human epidermal growth factor receptor (HER) 2 signals (1, 2). HER2 signals play an important role in HER2-positive

Correspondence to: Dr. Shinichiro Kashiwagi, Osaka City University Graduate School of Medicine, 1-4-3 Asahi-machi, Abeno-ku, Osaka 545-8585, Japan. Tel: +81 666453838, Fax: +81 666466450, email: spqv9ke9@view.ocn.ne.jp

Key Words: HER2-positive breast cancer, tumor-infiltrating lymphocytes, pertuzumab, trastuzumab, immune microenvironment. breast cancer (HER2-BC) (3-5), the prognosis of which has been greatly improved by anti-HER2 therapy, mainly with trastuzumab $(6,7)$. Large clinical trials have also shown that overall survival (OS) can be extended by treatment with pertuzumab $(8,9)$, trastuzumab (a humanized monoclonal antibody), and trastuzumab emtansine (T-DM1; an antibodydrug conjugate) (10). In clinical practice, chemotherapy with the TPD regimen (trastuzumab, pertuzumab, and docetaxel) has become the first-line therapy for advanced HER2-BC (8, 11). The question why the TPD regimen prolongs OS, which is seen as difficult to accomplish in breast cancer, has since arisen. The Kaplan-Meier curve of OS in the CLEOPATRA (Clinical Evaluation of Pertuzumab and Trastuzumab) trial exhibited a delayed separation curve that is characteristic of immunotherapy, and hence, it has been surmised that the TPD regimen takes part in the tumor immune response $(8,9)$.

Monitoring the host microenvironments of cancer plays a significant role in predicting the efficacy of chemotherapy and patient prognosis $(12,13)$. Recently, there has been an increasing number of reports morphologically evaluating tumor-infiltrating lymphocytes (TILs) and demonstrating their clinical implications in breast cancer (14-20). We previously reported on the clinical validity and benefit of evaluation of TILs during neoadjuvant chemotherapy (NAC) (21). In the present study, we carried out a clinical pathological verification of the TPD regimen by monitoring the immune microenvironment via TILs.

TILs were examined in the CLEOPATRA trial. In a subset that used the TPD regimen, the high-TILs group (>20\%) exhibited longer PFS and OS than the low-TILs group (22). However, significant differences with the placebo group were not confirmed. Thus, it was considered desirable to investigate real-world patients, not merely those who meet 
the inclusion criteria of a clinical trial. If assessing TILs could be used to predict the therapeutic effect of chemotherapy with the TPD regimen, high-cost drugs could be used more efficiently, which could greatly reduce the burden for patients with advanced HER2-BC.

Chemotherapy with the TPD regimen has been established as the first-line therapy for advanced HER2-BC, and its clinical drug properties and how it influences tumor microenvironments have become topics of interest. In this study, we evaluated and clinically verified the impact that chemotherapy with a TPD regimen against advanced HER2-BC has on immune microenvironments, using TILs as indicators.

\section{Patients and Methods}

Patient background. TPD regimen chemotherapy was administered to 24 patients with locally advanced or metastatic breast cancer from September 2013 to November 2015 at Osaka City University Hospital, Osaka, Japan. The median follow-up period for the assessment of progression-free survival (PFS) was 33 weeks (range $=9-105$ weeks) and for overall survival (OS) the median follow-up time was 53 weeks (range $=16-105$ weeks). The overall response rate (ORR) [Complete Response (CR) + Partial Response (PR)], clinical benefit rate (CBR) [CR + PR + Stable Disease (SD) $>24$ weeks], disease control rate (DCR) $[\mathrm{CR}+\mathrm{PR}+\mathrm{SD}]$, PFS and OS were calculated to assess the efficacy of this regimen. Breast cancer was confirmed histologically by core needle biopsy and staged by systemic imaging using computed tomography (CT), ultrasonography (US), and bone scintigraphy. Additionally, based on the immunohistochemical expression of estrogen receptor (ER), progesterone receptor (PgR), HER2 and Ki67, the tumors were categorized into the following immunophenotypes: luminal A (ER+ and/or PgR+, HER2-, Ki67-low), luminal B (ER+ and/or PgR+, HER2+: luminal HER2) (ER+ and/or PgR+, HER2-, Ki67-high), HER2 enriched (ER-, PgR-, and HER2+), and TNBC (negative for ER, PgR and HER2) (1). In this study, HER2 enriched and luminal HER2 tumors were considered to be HER2-BC.

The TPD regimen consists of trastuzumab, pertuzumab, and docetaxel $(8,9,11)$. The loading dose of trastuzumab is $8 \mathrm{mg} / \mathrm{kg}$ and that of pertuzumab is $840 \mathrm{mg}$. The maintenance dose of trastuzumab is $6 \mathrm{mg} / \mathrm{kg}$ and that of pertuzumab is $420 \mathrm{mg}$ every 3 weeks until disease progression. Typically, a dose of docetaxel is $75 \mathrm{mg} / \mathrm{m}^{2} / 3$ weeks for six cycles, but patients who are insufficiently healthy received 60 or $50 \mathrm{mg} / \mathrm{m}^{2}$ of docetaxel for the first dose. If their doctors decided that it is possible to continue treatment with docetaxel, the patients underwent 6 more cycles, while in the case of serious side effects, docetaxel was reduced 20 or $25 \%$ or discontinued. In this study, chemotherapy was administered to all patients on an outpatient basis. The chemotherapy protocol was followed until onset of progressive disease (PD) or severe adverse effects. The antitumor effect of the treatment was evaluated according to RECIST (Response Evaluation Criteria in Solid Tumors) version 1.1 (23).

The morphology of the tumor was evaluated using conventional hematoxylin and eosin (HE) staining, and the expression levels of ER, PgR, HER2 and Ki67 were evaluated using immunostaining on core needle biopsy (CNB) or vacuum-assisted biopsy (VAB) specimens obtained prior to the start of chemotherapy with the TPD regimen. In the cases of untreated metastatic breast cancer, biopsy for diagnosis as breast cancer was studied. In the case of recurrent, biopsy for diagnosis as recurrent or surgical specimen of first-line treatment was studied. The pathological diagnosis was made by several experienced pathologists specializing in cancer. OS was evaluated on a daily basis over the period from the date of treatment commencement to death. PFS was evaluated on a daily basis from the period from the date of treatment commencement to the date of death or confirmation of PD, whichever came earlier.

Ethics statement. This study was conducted at Osaka City University Graduate School of Medicine, Osaka, Japan, according to the Reporting Recommendations for Tumor Marker prognostic Studies (REMARK) guidelines and a retrospectively written research, pathological evaluation, and statistical plan (24). The study has a retrospective chart review study design. Written informed consent was obtained from all patients. This research conformed to the provisions of the Declaration of Helsinki of 2013. The study protocol was approved by the Ethics Committee of Osaka City University (\#926).

Histopathological evaluation of TILs. At the time of breast cancer diagnosis, TILs were evaluated on CNB or VAB specimens by measuring the percentage of area occupied by lymphocytes on the HEstained tumor section as reported by Salgado et al. (14). The area of TILs surrounding the stained cancer cells was quantitatively measured in each field of view at $400 \mathrm{X}$ magnification $(25,26)$. If the area of the stroma with lymphoplasmacytic infiltration around invasive tumor-cell nests was $>50 \%, 10-50 \%$, or $\leq 10 \%$, the corresponding score assigned was 3,2,1, or 0, respectively (Figure 1). TILs were judged as "high" for specimens with scores 2 or more, and "low" for scores of 1 and 0. Histopathological evaluation of TILs was performed by two professional breast cancer pathologists, who were kept blinded to clinical information including that on treatment and outcome.

Statistical analysis. Statistical analysis was performed using the statistical software package SPSS version 19.0 (IBM, Armonk, NY, USA). Associations between TILs and clinicopathological variables were examined using chi-squared tests or Fisher's exact test. Multivariable analysis of pathological complete response (pCR) was carried out using a binary logistic regression model. The Kaplan-Meier method was used to estimate PFS and OS, and the results were compared between groups with log-rank tests. The Cox proportional hazards model was used to compute univariable and multivariable hazards ratios (HR) for the study parameters with $95 \%$ confidence intervals (CI), and these were used in a backward stepwise method for variable selection in multivariate analyses. A $p$-value $<0.05$ was considered significant. Cutoff values for the biomarkers included in this study were chosen before statistical analysis.

\section{Results}

Clinical effects of TPD regimen chemotherapy. The subjects included 24 patients who underwent chemotherapy using TPD regimen against inoperable or metastatic/recurrent breast cancer. Docetaxel was administered concomitantly a mean 6 times (range $=1-8$ times). All patients were female, with a median age of 63 years. A total of 14 patients $(58.3 \%)$ were suffering from visceral metastases at the start of treatment. The sites of metastasis included, in order of decreasing prevalence: lung, 8 cases $(33.3 \%)$; bone, 7 cases (29.2\%); liver, 6 cases (25.0\%); brain, 2 cases (8.3\%); lymph 

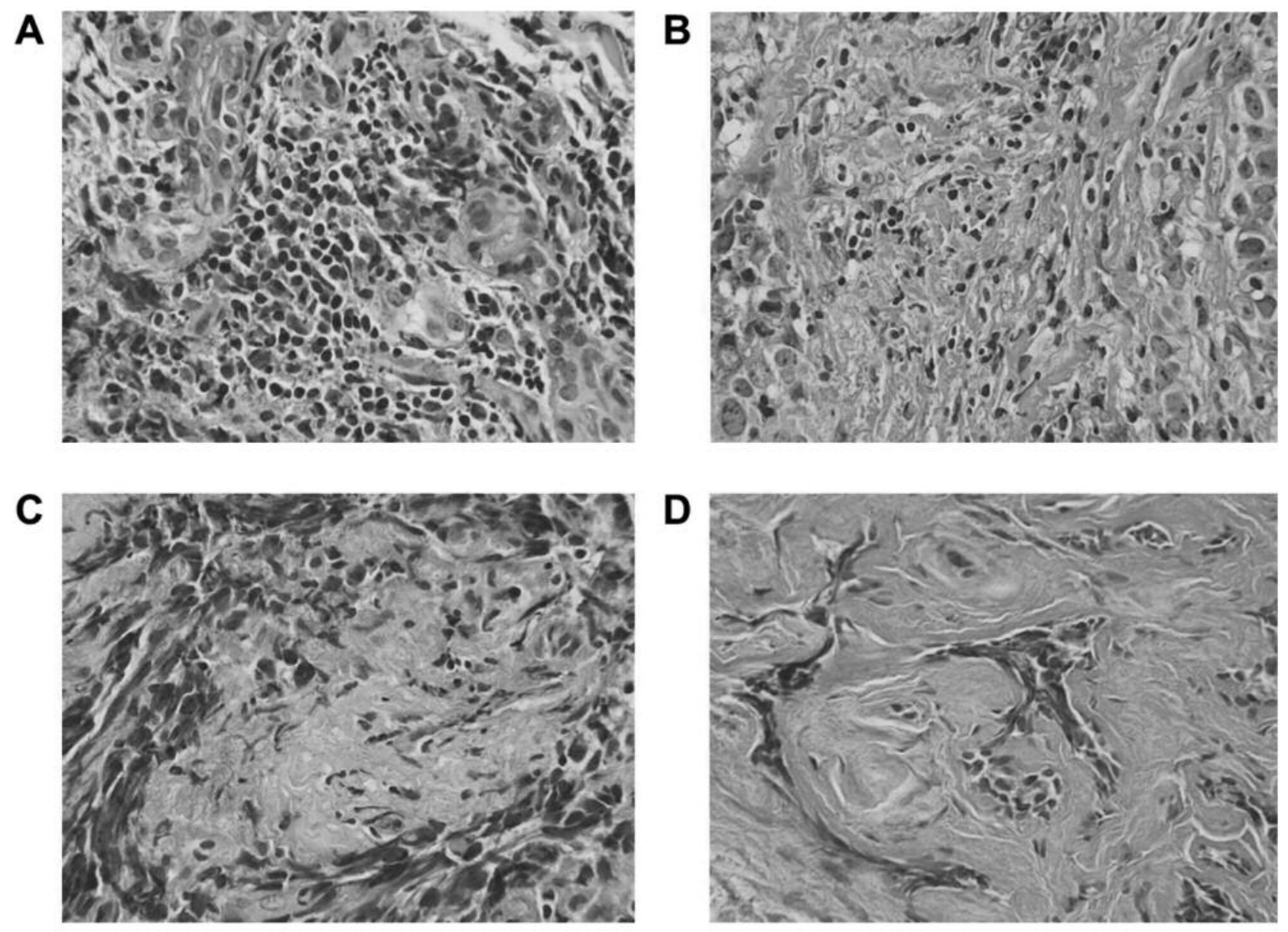

Figure 1. The area of TILs in the stroma surrounding the stained cancer cells was quantitatively measured in each field under $400 \times$ magnification. The areas of in situ carcinomas and crush artifacts were not included. Proportional scores were defined as 3, 2, 1, and 0 if the area of stroma with lymphoplasmacytic infiltration around the invasive tumor cell nests was $>50 \%(a) ;>10-50 \%(b) ; \leq 10 \%$ (b); and absent (d), respectively.

node, $8(33.3 \%)$; soft tissue, $7(29.2 \%)$. In the Intrinsic subtype, 16 cases $(66.7 \%)$ were of the HER2-enriched type and 8 cases $(33.3 \%)$ were of the Luminal-HER2 type (Table I). The clinical effects of TPD regimen chemotherapy were as follows: ORR, $87.5 \%$ (21/24); CBR, 91.7\% (22/24); DCR, $100.0 \%(24 / 24)$. When viewed according to the intrinsic subtype, the ORR rate was found to be $87.5 \%(14 / 16)$ in the HER2-enriched cases and 87.5\% (7/8) in the Luminal HER2 cases (Table II). In 12 cases $(50.0 \%)$, the treatment was successful and led to surgery.

Tumor-infiltrating lymphocytes in TPD regimen chemotherapy cases. The number of TILs was evaluated in every sample and ranged from 0 to 89 (mean=15; median=17; standard deviation 5). Of the 24 HER2-BC cases, there were 16 cases $(66.7 \%)$ in the high-TILs group and 8 cases $(33.3 \%)$ in the low-TILs group. Of the HER2 enriched cases, there were 11 cases (68.8\%) in the high-TILs group and 5 cases $(31.2 \%)$ in the low-TILs group. Of the luminal HER 2 cases, there were 5 cases $(62.5 \%)$ in the highTILs group and 3 cases $(37.5 \%)$ in the low-TILs group. Among the HER2-BC cases, the ORR was significantly higher in the high-TILs group than in the low-TILs group $(p=0.028)$; no correlations were observed in the HER2 enriched or luminal HER2 cases (Table III). Correlations were not observed with any other clinical pathological factors. Significant extension of the PFS and OS was found in the high-TILs group compared with the low-TILs group ( $p=0.017$, log-rank) ( $p=0.013$, log-rank) (Figure 2). In addition, according to univariate and multivariate statistical analysis, high TILs significantly extend PFS $(p=0.030$, $\mathrm{HR}=0.193) \quad(p=0.015, \mathrm{HR}=0.104) \quad($ Table VI) (Figure 3). However, with only recurrent cases, no significant extension of the PFS and OS was found in the high-TILs group compared with the low-TILs group ( $p=0.548, \log$-rank) $(p=0.179, \log$-rank) (Figure 4). 

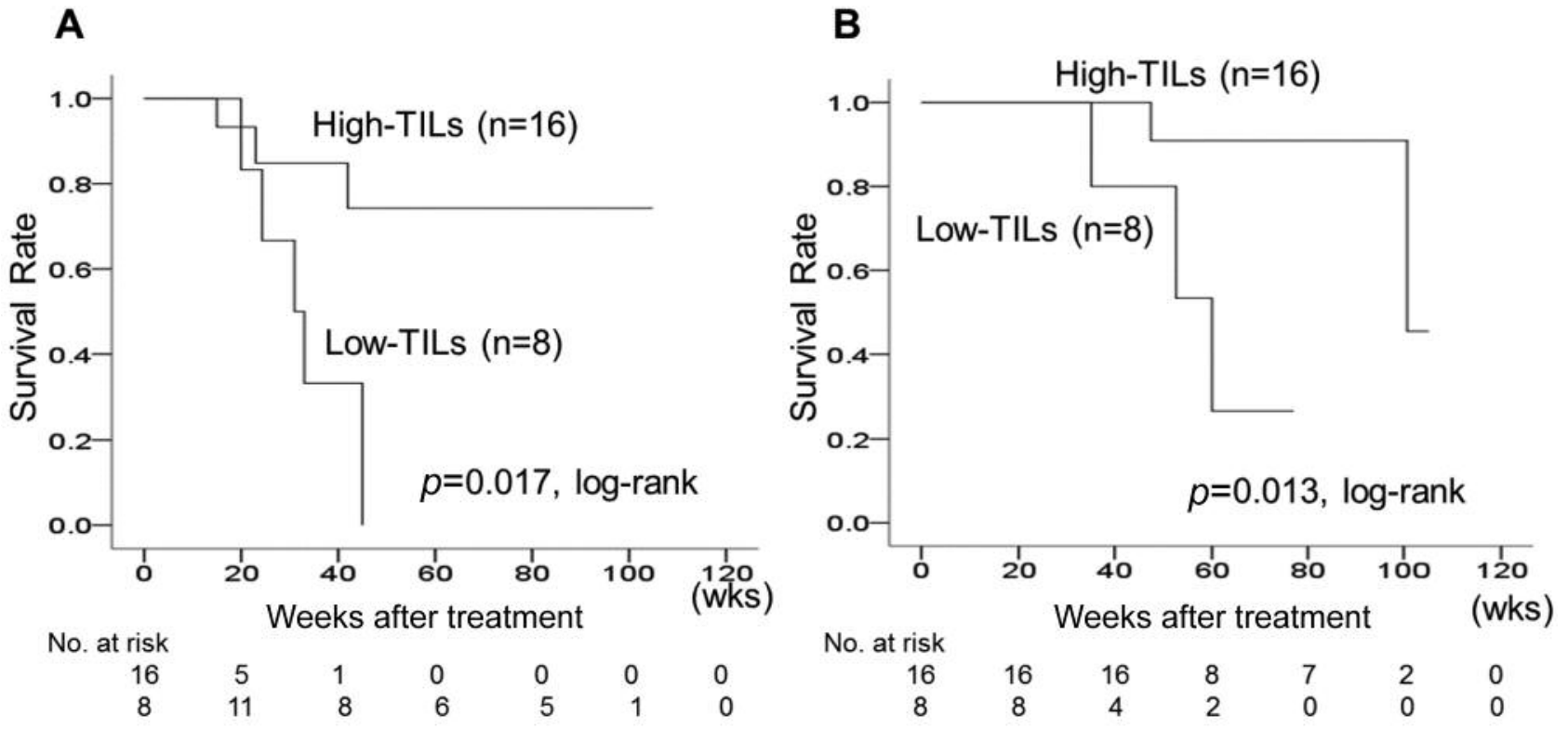

Figure 2. In an analysis of outcomes, significant extension of the progression-free survival and overall survival was found in the high-TILs group compared to the low-TILs group ( $p=0.017, \log$-rank) (a) $(p=0.013, \log$-rank) (b).

Table I. Demographic data of 24 patients with TPD regimen chemotherapy for advanced HER2-positive breast cancer.

\begin{tabular}{llc}
\hline Parameters $(\mathrm{n}=24)$ & & Number of patients $(\%)$ \\
\hline Age (years old) & & $63 \pm 12$ \\
Degree of progress & Locally advanced/visceral metastases & $10(41.7 \%) / 14(58.3 \%)$ \\
Stage & III/IV/recurrence & $5(20.8 \%) / 8(33.3 \%) / 11(45.9 \%)$ \\
Site of metastases & Lung/bone/liver/brain/lymph node/soft tissue & $8(33.3 \%) / 7(29.2 \%) / 6(25.0 \%) / 2(8.3 \%) / 8(33.3 \%) / 7(29.2 \%)$ \\
Treatment line & First/others & $15(62.5 \%) / 9(37.5 \%)$ \\
Hormone receptor & Negative/positive & $16(66.7 \%) / 8(33.3 \%)$ \\
Ki67 & Negative/positive & $12(50.0 \%) / 12(50.0 \%)$ \\
Intrinsic subtype & HER2 enriched/luminal HER2 & $16(66.7 \%) / 8(33.3 \%)$
\end{tabular}

TPD: Trastuzumab, pertuzumab, docetaxel; HER: human epidermal growth factor receptor.

\section{Discussion}

The CLEOPATRA trial report ushered in a new era for the treatment of advanced HER2-BC, and chemotherapy with the TPD regimen has become the first-line therapy $(8,9,11)$. However, apart from HER2 expression, no biomarkers that can predict the therapeutic effect have been discovered (6, 7). A biomarker is needed to help select patients in whom including pertuzumab in the treatment regimen would increase the effectiveness of the treatment. The CLEOPATRA trial demonstrated that chemotherapy with the TPD regimen prolongs OS. Improvement in the immune microenvironment is thought to be involved in bringing this about $(8,22)$.
Trastuzumab and pertuzumab possess antibody-dependent cellular cytotoxicity (ADCC) activity, and are thought to suppress tumor proliferation not only by blocking the HER2 signal pathway, but also by increasing immune activity of the host by inducing natural killer (NK) cells (27). Further, trastuzumab therapy has been reported to increase the expression of TILs in breast cancer tissue. It has been surmised that trastuzumab and pertuzumab act on tumor immunity through avenues besides ADCC activity (22). It may be possible to use TILs to evaluate how these mechanisms affect the immune microenvironment in HER2-BC (28).

The HER2-BC subsets HER2-enriched and luminal HER did not exhibit differences in ORR in the CLEOPATRA trial, which indicates that chemotherapy with the TPD 


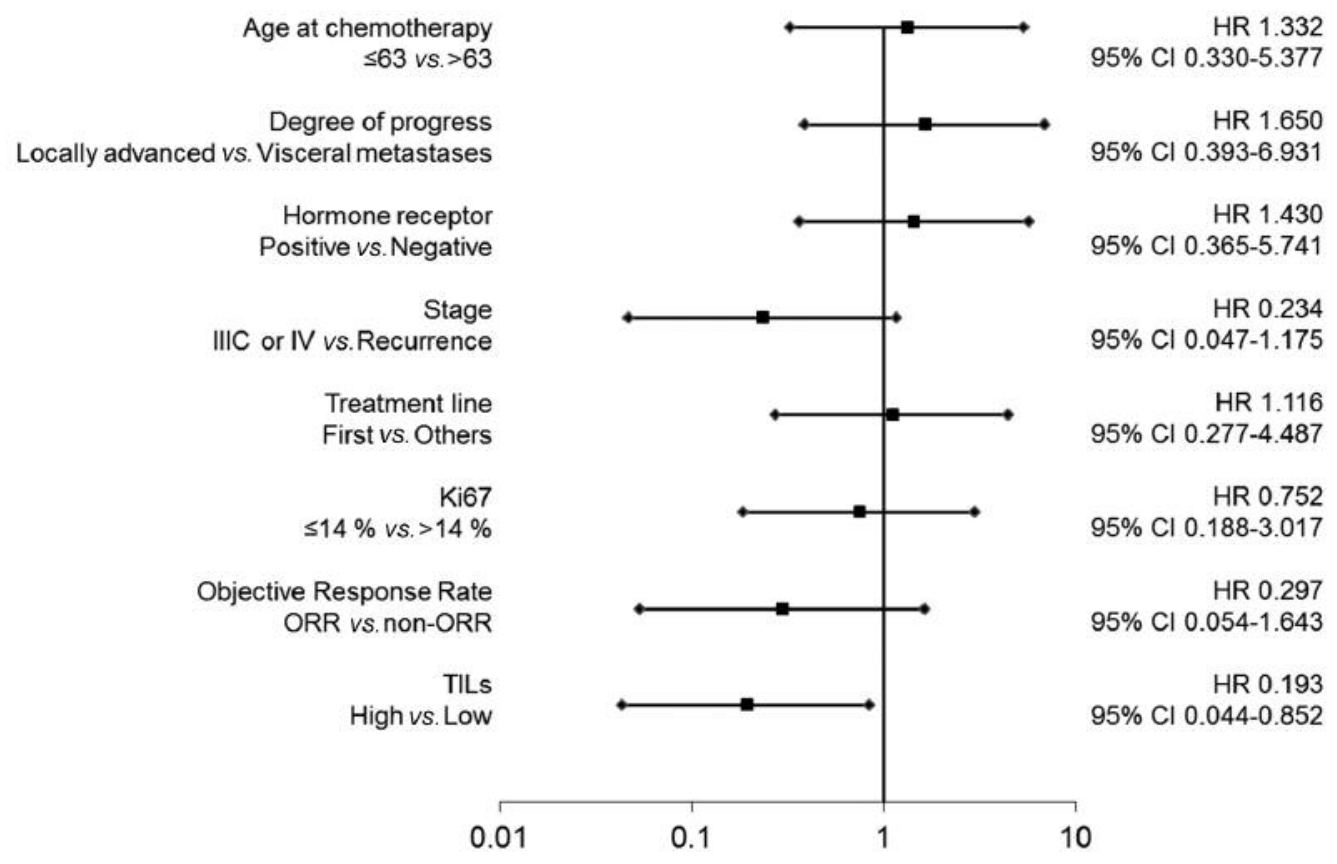

Figure 3. Forest plots. Univariate analysis of patients belonging to the high-TILs group showed that this factor contributed significantly to prolonging progression-free survival ( $p=0.030$, hazard ratio $=0.193,95 \%$ confidence intervals $=0.044-0.852)$.

Table II. Clinical effects of TPD regimen chemotherapy in advanced HER2-positive breast cancer subtype.

\begin{tabular}{lccc}
\hline & All breast cancer $(\mathrm{n}=24)$ & \multicolumn{2}{c}{ Intrinsic subtype } \\
\cline { 3 - 4 } & & HER2 enriched $(\mathrm{n}=16)$ & Luminal HER2 (n=8) \\
\hline ORR; Objective Response Rate & $21(87.5 \%)$ & $14(87.5 \%)$ & $7(87.5 \%)$ \\
CBR; Clinical Benefit Response & $22(91.7 \%)$ & $15(93.8 \%)$ & $7(87.5 \%)$ \\
DCR; Disease Control Rate & $24(100 \%)$ & $16(100 \%)$ & $8(100 \%)$ \\
CR; Complete Response & $2(8.3 \%)$ & $2(12.5 \%)$ & $0(0 \%)$ \\
PR; Partial Response & $19(79.2 \%)$ & $12(75.0 \%)$ & $7(87.5 \%)$ \\
SD; Stable Disease >24wks & $1(4.2 \%)$ & $1(6.25 \%)$ & $0(0 \%)$ \\
SD; Stable Disease & $2(8.3 \%)$ & $1(6.25 \%)$ & $1(12.5 \%)$ \\
PD; Progressive Disease & $0(0 \%)$ & $0(0 \%)$ & $0(0 \%)$ \\
NE; Not Evaluable & $0(0 \%)$ & $0(0 \%)$ & $0(0 \%)$ \\
\hline
\end{tabular}

TPD: Trastuzumab, pertuzumab, docetaxel; HER: human epidermal growth factor receptor.

regimen is effective regardless of the presence or absence of hormone receptor expression $(8,9)$. In the present study, the analysis of the HER2-enriched and luminal HER subsets did not show correlations between TILs and ORR for either type. Functional crosstalk has been indicated in the ER and HER2 signaling pathways (29), but the presence or absence of hormone receptor expression is thought to have little influence on the immune microenvironment in HER2-BC, which is a subtype with a high level of immune activity $(17,18,27)$.
For HER2-BC, the high immune activity of the TPD regimen not only shrinks the tumor by blocking the HER2 signal cascade, but is thought to prolong survival by improving the microenvironment through an immune response $(30,31)$. In addition, patients with cancer are thought to have increased levels of regulatory $T$ cells (Tregs) (21), so the concomitant use of taxane drugs, that suppress Tregs, is thought to activate ADCC in the host through Treg suppression $(30,32)$. TILs assessments before starting treatment for HER2-BC could be used as markers for 

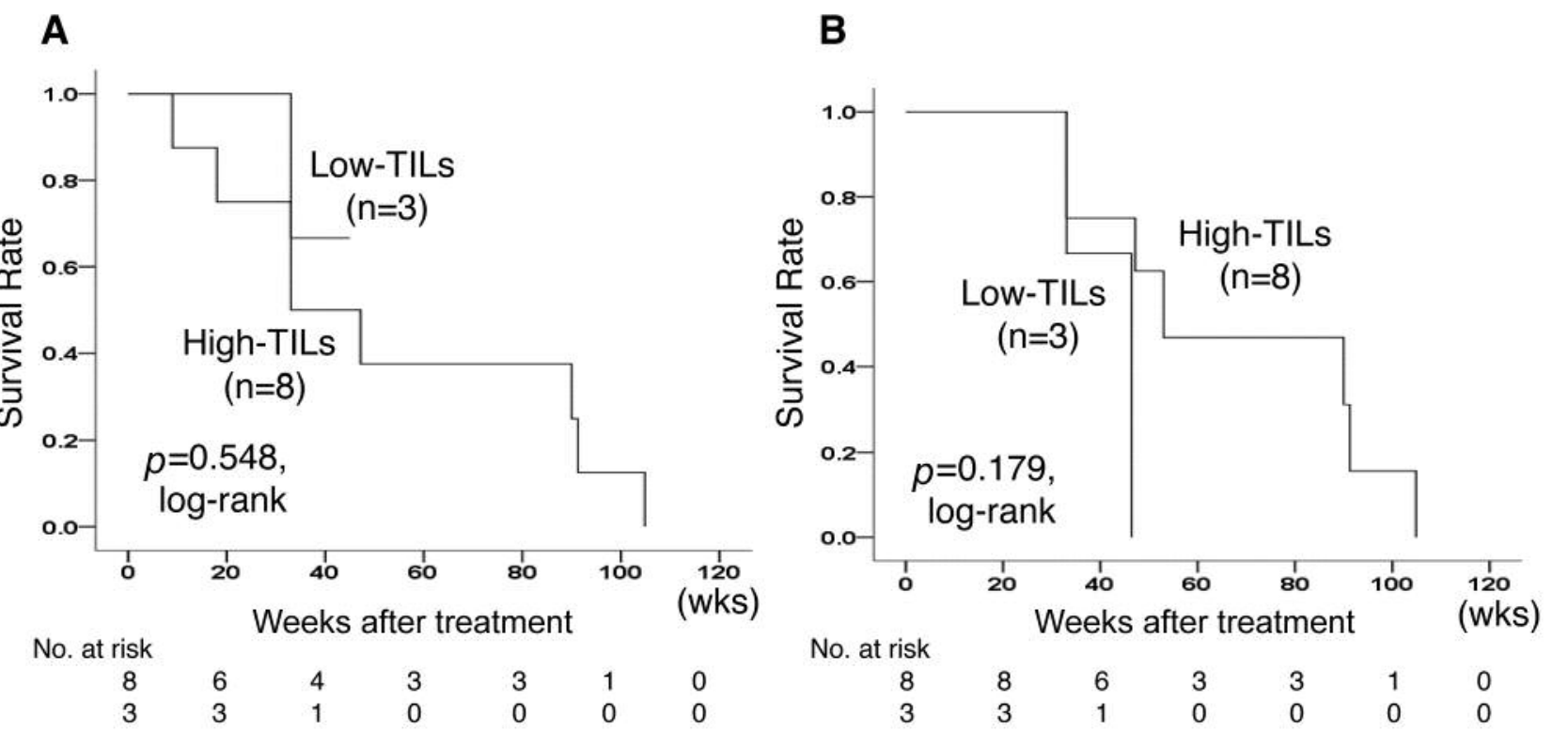

Figure 4. With only recurrent cases, no significant extension of the PFS and OS was found in the high-TILs group compared to the low-TILs group $(p=0.548, \log$-rank $)(p=0.179, \log$-rank $)$.

Table III. Correlations between tumor-infiltrating lymphocytes and clinicopathological parameters in 24 patients with TPD regimen chemotherapy for advanced HER2-positive breast cancer.

\begin{tabular}{|c|c|c|c|c|c|c|c|c|c|}
\hline \multirow[t]{2}{*}{ Parameters } & \multicolumn{2}{|c|}{ HER2-positive ( $\mathrm{n}=24)$} & \multirow[b]{2}{*}{$p$-Value } & \multicolumn{2}{|c|}{ HER2 enriched $(n=16)$} & \multirow[b]{2}{*}{$p$-Value } & \multicolumn{2}{|c|}{ Luminal HER2 $(n=8)$} & \multirow[b]{2}{*}{$p$-Value } \\
\hline & High $(n=16)$ & Low $(n=8)$ & & $\operatorname{High}(\mathrm{n}=11)$ & Low $(n=5)$ & & $\operatorname{High}(n=5)$ & Low $(n=3)$ & \\
\hline \multicolumn{10}{|l|}{ Age at chemotherapy } \\
\hline$\leq 63$ & $9(56.3 \%)$ & $3(37.5 \%)$ & & $5(45.5 \%)$ & $2(40.0 \%)$ & & $4(80.0 \%)$ & $1(33.3 \%)$ & \\
\hline$>63$ & $7(43.7 \%)$ & $5(62.5 \%)$ & 0.333 & $6(54.5 \%)$ & $3(60.0 \%)$ & 0.635 & $1(20.0 \%)$ & $2(66.7 \%)$ & 0.286 \\
\hline \multicolumn{10}{|l|}{ Degree of progress } \\
\hline Locally advanced & $6(37.5 \%)$ & $4(50.0 \%)$ & & $3(27.3 \%)$ & $3(60.0 \%)$ & & $3(60.0 \%)$ & $1(33.3 \%)$ & \\
\hline Visceral metastases & $10(62.5 \%)$ & $4(50.0 \%)$ & 0.439 & $8(72.7 \%)$ & $2(40.0 \%)$ & 0.242 & $2(40.0 \%)$ & $2(66.7 \%)$ & 0.500 \\
\hline \multicolumn{10}{|l|}{ Stage } \\
\hline IIIC or IV & $8(50.0 \%)$ & $5(62.5 \%)$ & & $4(36.4 \%)$ & $3(60.0 \%)$ & & $4(80.0 \%)$ & $2(66.7 \%)$ & \\
\hline Recurrence & $8(50.0 \%)$ & $3(37.5 \%)$ & 0.444 & $7(63.6 \%)$ & $2(40.0 \%)$ & 0.365 & $1(20.0 \%)$ & $1(33.3 \%)$ & 0.643 \\
\hline \multicolumn{10}{|l|}{ Treatment line } \\
\hline First & $9(56.3 \%)$ & $6(75.0 \%)$ & & $7(63.6 \%)$ & $4(80.0 \%)$ & & $2(40.0 \%)$ & $2(66.7 \%)$ & \\
\hline Others & $7(43.7 \%)$ & $2(25.0 \%)$ & 0.332 & $4(36.4 \%)$ & $1(20.0 \%)$ & 0.484 & $3(60.0 \%)$ & $1(33.3 \%)$ & 0.500 \\
\hline \multicolumn{10}{|l|}{ Ki67 } \\
\hline Negative & $9(56.3 \%)$ & $3(37.5 \%)$ & & $6(54.5 \%)$ & $3(60.0 \%)$ & & $3(60.0 \%)$ & $0(0 \%)$ & \\
\hline Positive & $7(43.7 \%)$ & $5(62.5 \%)$ & 0.333 & $5(45.5 \%)$ & $2(40.0 \%)$ & 0.635 & $2(40.0 \%)$ & $3(100 \%)$ & 0.179 \\
\hline \multicolumn{10}{|l|}{ Objective response rate } \\
\hline ORR & $16(100 \%)$ & $5(62.5 \%)$ & & $11(100 \%)$ & $3(60.0 \%)$ & & $5(100 \%)$ & $2(66.7 \%)$ & \\
\hline non-ORR & $0(0 \%)$ & $3(37.5 \%)$ & 0.028 & $0(0 \%)$ & $2(40.0 \%)$ & 0.083 & $0(0 \%)$ & $1(33.3 \%)$ & 0.375 \\
\hline
\end{tabular}

TPD: Trastuzumab, pertuzumab, docetaxel. ORR: objective response rate; HER: human epidermal growth factor receptor.

monitoring the immune microenvironment of the host. Moreover, since TILs are used for prediction of the effects of treatments such as immunotherapy, they could contribute to establishing novel therapeutic strategies that combine anti-
HER2 therapy with immunotherapy. In the prognostic analyses, PFS and OS were higher in the high-TILs group than in the low-TILs group. The Kaplan-Meier curve in this study showed a tail plateau delayed separation curve, 
Table IV. Univariate and multivariate analysis with respect to progression-free survival in 24 patients with TPD regimen chemotherapy for advanced HER2-positive breast cancer.

\begin{tabular}{|c|c|c|c|c|c|c|c|}
\hline \multirow[b]{2}{*}{ Parameters } & & \multicolumn{3}{|c|}{ Univariate analysis } & \multicolumn{3}{|c|}{ Multivariate analysis } \\
\hline & & Hazard ratio & $95 \% \mathrm{CI}$ & $p$-Value & Hazard ratio & $95 \% \mathrm{CI}$ & $p$-Value \\
\hline Age at chemotherapy & $\leq 63 v s .>63$ & 1.332 & $0.330-5.377$ & 0.687 & & & \\
\hline Degree of progress & Locally advanced $v s$. visceral metastases & 1.650 & $0.393-6.931$ & 0.494 & & & \\
\hline Hormone receptor & Positive $v s$. negative & 1.430 & $0.365-5.741$ & 0.614 & & & \\
\hline Stage & IIIC or IV vs. recurrence & 0.234 & $0.047-1.175$ & 0.078 & 0.132 & $0.021-0.844$ & 0.032 \\
\hline Treatment line & First $v s$. others & 1.116 & $0.277-4.487$ & 0.878 & & & \\
\hline Ki67 & $\leq 14 \%$ vs. $>14 \%$ & 0.752 & $0.188-3.017$ & 0.688 & & & \\
\hline Objective response rate & ORR vs. non-ORR & 0.297 & $0.054-1.643$ & 0.164 & & & \\
\hline TILs & High vs. Low & 0.193 & $0.044-0.852$ & 0.030 & 0.104 & $0.017-0.649$ & 0.015 \\
\hline
\end{tabular}

CI: Confidence interval; ORR: objective response rate; TILs: tumor-infiltrating lympho.

suggesting that TPD chemotherapy contributes to a protective immune response. In other words, TPD chemotherapy not only shows high ORR, but also contributes to improvement of prognosis through the immune microenvironment.

In the present study, by evaluating TILs in biopsy samples in HER2-positive breast cancer with TPD chemotherapy was found to contribute to selection of the initial drug therapy. However, the fact that this study was a small-scale retrospective study is a limitation. Moreover, there are also differences in timing of sampling and post-treatment. But since it used realworld data that conforms to actual clinical practice, we consider it to be a significant investigation into how chemotherapy with the TPD regimen affects immune microenvironments.

Our results suggest that the monitoring of antitumor immune response using TILs might be a useful indicator in predicting the curative effects of TPD chemotherapy for HER2-positive breast cancer.

\section{Conflicts of Interest}

All Authors have no conflicts of interest to disclose.

\section{Acknowledgements}

The Authors would like to thank Yayoi Matsukiyo and Tomomi Ohkawa (Department of Surgical Oncology, Osaka City University Graduate School of Medicine) for their helpful advice regarding data management. This study was funded by grants from the Japan Society for the Promotion of Science (KAKENHI, Nos. 25461992, 26461957, and 17K10559) to Shinichiro Kashiwagi.

\section{References}

1 Goldhirsch A, Wood WC, Coates AS, Gelber RD, Thurlimann B, Senn HJ and Panel M: Strategies for subtypes - dealing with the diversity of breast cancer: highlights of the St. Gallen International Expert Consensus on the Primary Therapy of Early Breast Cancer 2011. Ann Oncol 22: 1736-1747, 2011.
2 Hortobagyi GN: Treatment of breast cancer. N Engl J Med 339: 974-984, 1998.

3 Slamon DJ, Godolphin W, Jones LA, Holt JA, Wong SG, Keith DE, Levin WJ, Stuart SG, Udove J and Ullrich A: Studies of the HER-2/neu proto-oncogene in human breast and ovarian cancer. Science 244: 707-712, 1989.

4 Chia S, Norris B, Speers C, Cheang M, Gilks B, Gown AM, Huntsman D, Olivotto IA, Nielsen TO and Gelmon K: Human epidermal growth factor receptor 2 overexpression as a prognostic factor in a large tissue microarray series of nodenegative breast cancers. J Clin Oncol 26: 5697-5704, 2008.

5 Slamon DJ, Clark GM, Wong SG, Levin WJ, Ullrich A and McGuire WL: Human breast cancer: correlation of relapse and survival with amplification of the HER-2/neu oncogene. Science 235: 177-182, 1987.

6 Slamon DJ, Leyland-Jones B, Shak S, Fuchs H, Paton V, Bajamonde A, Fleming T, Eiermann W, Wolter J, Pegram M, Baselga $J$ and Norton L: Use of chemotherapy plus a monoclonal antibody against HER2 for metastatic breast cancer that overexpresses HER2. N Engl J Med 344: 783-792, 2001.

7 Dawood S, Broglio K, Buzdar AU, Hortobagyi GN and Giordano SH: Prognosis of women with metastatic breast cancer by HER2 status and trastuzumab treatment: an institutionalbased review. J Clin Oncol 28: 92-98, 2010.

8 Baselga J, Cortes J, Kim SB, Im SA, Hegg R, Im YH, Roman L, Pedrini JL, Pienkowski T, Knott A, Clark E, Benyunes MC, Ross G, Swain SM and Group CS: Pertuzumab plus trastuzumab plus docetaxel for metastatic breast cancer. N Engl J Med 366: 109-119, 2012.

9 Baselga J, Cortes J, Im SA, Clark E, Ross G, Kiermaier A and Swain SM: Biomarker analyses in CLEOPATRA: a phase III, placebo-controlled study of pertuzumab in human epidermal growth factor receptor 2-positive, first-line metastatic breast cancer. J Clin Oncol 32: 3753-3761, 2014.

10 Verma S, Miles D, Gianni L, Krop IE, Welslau M, Baselga J, Pegram M, Oh DY, Dieras V, Guardino E, Fang L, Lu MW, Olsen S, Blackwell K and Group ES: Trastuzumab emtansine for HER2-positive advanced breast cancer. N Engl J Med 367: 1783-1791, 2012. 
11 Kawajiri H, Takashima T, Kashiwagi S, Noda S, Onoda N and Hirakawa K: Pertuzumab in combination with trastuzumab and docetaxel for HER2-positive metastatic breast cancer. Expert Rev Anticancer Ther 15: 17-26, 2015.

12 Couzin-Frankel J: Breakthrough of the year 2013. Cancer immunotherapy. Science 342: 1432-1433, 2013.

13 Hanahan D and Weinberg RA: Hallmarks of cancer: the next generation. Cell 144: 646-674, 2011.

14 Salgado R, Denkert C, Demaria S, Sirtaine N, Klauschen F, Pruneri G, Wienert S, Van den Eynden G, Baehner FL, PenaultLlorca F, Perez EA, Thompson EA, Symmans WF, Richardson AL, Brock J, Criscitiello C, Bailey H, Ignatiadis M, Floris G, Sparano J, Kos Z, Nielsen T, Rimm DL, Allison KH, Reis-Filho JS, Loibl S, Sotiriou C, Viale G, Badve S, Adams S, WillardGallo K, Loi S, and International TWG: The evaluation of tumor-infiltrating lymphocytes (TILs) in breast cancer: recommendations by an International TILs Working Group 2014. Ann Oncol 26: 259-271, 2015.

15 Savas P, Salgado R, Denkert C, Sotiriou C, Darcy PK, Smyth MJ and Loi S: Clinical relevance of host immunity in breast cancer: from TILs to the clinic. Nat Rev Clin Oncol 13: 228-241, 2016.

16 Adams S, Gray RJ, Demaria S, Goldstein L, Perez EA, Shulman LN, Martino S, Wang M, Jones VE, Saphner TJ, Wolff AC, Wood WC, Davidson NE, Sledge GW, Sparano JA and Badve SS: Prognostic value of tumor-infiltrating lymphocytes in triplenegative breast cancers from two phase III randomized adjuvant breast cancer trials: ECOG 2197 and ECOG 1199. J Clin Oncol 32: 2959-2966, 2014.

17 Denkert C, von Minckwitz G, Brase JC, Sinn BV, Gade S, Kronenwett R, Pfitzner BM, Salat C, Loi S, Schmitt WD, Schem C, Fisch K, Darb-Esfahani S, Mehta K, Sotiriou C, Wienert S, Klare P, Andre F, Klauschen F, Blohmer JU, Krappmann K, Schmidt M, Tesch H, Kummel S, Sinn P, Jackisch C, Dietel M, Reimer T, Untch M and Loibl S: Tumor-infiltrating lymphocytes and response to neoadjuvant chemotherapy with or without carboplatin in human epidermal growth factor receptor 2positive and triple-negative primary breast cancers. J Clin Oncol 33: 983-991, 2015.

18 Loi S, Michiels S, Salgado R, Sirtaine N, Jose V, Fumagalli D, Kellokumpu-Lehtinen PL, Bono P, Kataja V, Desmedt C, Piccart MJ, Loibl S, Denkert C, Smyth MJ, Joensuu H and Sotiriou C: Tumor infiltrating lymphocytes are prognostic in triple negative breast cancer and predictive for trastuzumab benefit in early breast cancer: results from the FinHER trial. Ann Oncol 25: 1544-1550, 2014.

19 Loi S, Sirtaine N, Piette F, Salgado R, Viale G, Van Eenoo F, Rouas G, Francis P, Crown JP, Hitre E, de Azambuja E, Quinaux E, Di Leo A, Michiels S, Piccart MJ and Sotiriou C: Prognostic and predictive value of tumor-infiltrating lymphocytes in a phase III randomized adjuvant breast cancer trial in node-positive breast cancer comparing the addition of docetaxel to doxorubicin with doxorubicin-based chemotherapy: BIG 02-98. J Clin Oncol 31: 860-867, 2013.

20 Loi S: Tumor-infiltrating lymphocytes, breast cancer subtypes and therapeutic efficacy. Oncoimmunology 2: e24720, 2013.

21 Asano Y, Kashiwagi S, Goto W, Kurata K, Noda S, Takashima T, Onoda N, Tanaka S, Ohsawa M and Hirakawa K: Tumourinfiltrating CD8 to FOXP3 lymphocyte ratio in predicting treatment responses to neoadjuvant chemotherapy of aggressive breast cancer. Br J Surg 103: 845-854, 2016.
22 Luen SJ, Salgado R, Fox S, Savas P, Eng-Wong J, Clark E, Kiermaier A, Swain SM, Baselga J, Michiels S and Loi S: Tumour-infiltrating lymphocytes in advanced HER2-positive breast cancer treated with pertuzumab or placebo in addition to trastuzumab and docetaxel: a retrospective analysis of the CLEOPATRA study. Lancet Oncol 18: 52-62, 2017.

23 Eisenhauer EA, Therasse P, Bogaerts J, Schwartz LH, Sargent D, Ford R, Dancey J, Arbuck S, Gwyther S, Mooney M, Rubinstein L, Shankar L, Dodd L, Kaplan R, Lacombe D and Verweij J: New response evaluation criteria in solid tumours: revised RECIST guideline (version 1.1). Eur J Cancer 45: 228247, 2009.

24 McShane LM, Altman DG, Sauerbrei W, Taube SE, Gion M, Clark GM and Statistics Subcommittee of the NCIEWGoCD: Reporting recommendations for tumor marker prognostic studies. J Clin Oncol 23: 9067-9072, 2005.

25 Ono M, Tsuda H, Shimizu C, Yamamoto S, Shibata T, Yamamoto H, Hirata T, Yonemori K, Ando M, Tamura K, Katsumata N, Kinoshita T, Takiguchi Y, Tanzawa $\mathrm{H}$ and Fujiwara Y: Tumor-infiltrating lymphocytes are correlated with response to neoadjuvant chemotherapy in triple-negative breast cancer. Breast Cancer Res Treat 132: 793-805, 2012.

26 Kashiwagi S, Asano Y, Goto W, Takada K, Takahashi K, Noda S, Takashima T, Onoda N, Tomita S, Ohsawa M, Hirakawa K and Ohira M: Use of Tumor-infiltrating lymphocytes (TILs) to predict the treatment response to eribulin chemotherapy in breast cancer. PLoS One 12: e0170634, 2017.

27 Scheuer W, Friess T, Burtscher H, Bossenmaier B, Endl J and Hasmann M: Strongly enhanced antitumor activity of trastuzumab and pertuzumab combination treatment on HER2positive human xenograft tumor models. Cancer Res 69: 93309336, 2009.

28 Ingold Heppner B, Untch M, Denkert C, Pfitzner BM, Lederer B, Schmitt W, Eidtmann H, Fasching PA, Tesch H, Solbach C, Rezai M, Zahm DM, Holms F, Glados M, Krabisch P, Heck E, Ober A, Lorenz P, Diebold K, Habeck JO and Loibl S: Tumorinfiltrating lymphocytes: a predictive and prognostic biomarker in neoadjuvant-treated HER2-positive breast cancer. Clin Cancer Res 22: 5747-5754, 2016.

29 Dati C, Antoniotti S, Taverna D, Perroteau I and De Bortoli M: Inhibition of c-erbB-2 oncogene expression by estrogens in human breast cancer cells. Oncogene 5: 1001-1006, 1990.

30 Zitvogel L, Kepp $\mathrm{O}$ and Kroemer G: Immune parameters affecting the efficacy of chemotherapeutic regimens. Nat Rev Clin Oncol 8: 151-160, 2011.

31 Vacchelli E, Galluzzi L, Fridman WH, Galon J, Sautes-Fridman C, Tartour E and Kroemer G: Trial watch: Chemotherapy with immunogenic cell death inducers. Oncoimmunology 1: 179-188, 2012.

32 Yaguchi T, Sumimoto H, Kudo-Saito C, Tsukamoto N, Ueda R, Iwata-Kajihara T, Nishio H, Kawamura N and Kawakami Y: The mechanisms of cancer immunoescape and development of overcoming strategies. Int J Hematol 93: 294-300, 2011.

Received August 25, 2017

Revised September 14, 2017

Accepted September 19, 2017 